\title{
Rural household energy consumption behavior with neural network approach: A case study
}

\author{
Sheng Cheng*, Xiongbiao Xie, Giedon Kwaku Minua Ampofo, Jiping Chu \\ School of Economics and Management, China University of Geosciences (Wuhan), Wuhan 430074, China
}

Corresponding Author Email: adamparadise@ sina.com

https://doi.org/10.18280/ijht.360442

Received: 19 February 2018

Accepted: 30 May 2018

\section{Keywords:}

energy consumption, influencing factors, rural survey, neural network

\begin{abstract}
Rural household energy consumption is an important component of national energy consumption and plays a vital role in rural economic and ecological environment development. In this paper, the energy consumption of 1126 households in four typical agricultural provinces was investigated. In addition, multilayer perceptron neural network is adopted to conduct variables selection. Moreover, Logit, Tobit and multiple regression models are used to reveal the impact of different factors on rural resident choice and quantity behavior. The results show that family size, market distance, education level, farmland area and occupation affect farmers' energy choices and quantity consumption behavior to varying degrees. The differences of energy availability and convenience caused by the difference of geographical features are important factors that affect the energy consumption behavior of farmers. Income level is a key determinant of transition of energy consumption behavior, which however is not sensitive to coal. We hold the opinion that the key to improve rural energy structure in China is to boost the income level of rural residents. Meanwhile, rural energy consumption should be included in the national energy strategy framework. The government should increase the investment on the research and implementation of the renewable energy and use economic measures such as taxes and subsidies to reduce initial installed costs and operating costs so as to speed up the of upgrading rural energy consumption structure.
\end{abstract}

\section{INTRODUCTION}

Household energy consumption is the ultimate terminal of national energy consumption and the main driving factor of energy consumption in manufacturing industry, service industry and transportation. Traditionally, it is generally believed that heavy chemical industry is the main "culprit" of energy consumption and environmental pollution. However, with the improvement of industrial energy efficiency, government regulation in high energy consumption and high pollution industries, the increase in global energy demand and, carbon emissions mainly come from household energy consumption. Since the reform and opening up policy with the rapid development of China's rural economy, the demand for energy consumption in rural areas has risen sharply, and the energy consumption structure is shifting from non-commercial to commercial energy source [3]. From the perspective of per capita consumption, the living expenses of rural residents have increased substantially, from $60 \mathrm{kgce}$ in 1980 to $325 \mathrm{kgce}$ in 2014, an increase of nearly 4.4 times, while that of urban residents has increased from $332 \mathrm{kgce}$ to $364 \mathrm{kgce}$, only an increase of $9.6 \%$. Due to long-term urban preference development in China, urban energy consumption per capita is similar to the overall energy consumption with a marked period of decline from 1980 to 2000 . However, most studies believe that this is the result of energy efficiency rather than the adjustment of energy structure $[8,12]$. The fastest period of energy consumption of urban residents is from 2001 to 2014, which has an increase of $73.3 \%$, and it is still far less than the growth rate of rural residents living energy consumption. From the perspective of structure, the consumption of traditional biomass energy in rural areas dropped from $71 \%$ in 1980 to $34 \%$ in 2005 , and the commercial energy consumption increased from $17 \%$ to $44 \%$ [29].

For quite a long time, rural energy consumption does not attract sufficient attention, which is an inevitable result of energy development strategy, planning and policies based on the urban-rural dual structure, which makes the rural energy system under a long-term isolation state from the national framework of energy strategy. This statement not only seriously hinders the healthy and sustainable development of the rural economy but also fails to meet the goal of energy fairness. However, such state of being outside of the national energy strategy requires that rural energy development strategy not only meets the basic needs of rural economic development, ensures national energy security, but also bears the historical mission of delaying climate deterioration [3]. Meanwhile, due to the low proportion of rural energy consumption in China's domestic energy demand, the huge negative effect of extensive energy use by rural residents on the environment and residents' health has long been neglected. Due to the obvious regional differences in rural areas, the diversity of the energy consumed and the heterogeneity of family units make it difficult for the government to control or adjust the household energy consumption behaviors of rural residents through systematic regulatory tools. And the green transformation of rural household energy consumption behavior has been neglected for a long time. Following the theory of energy ladder, with the improving of household income and public energy facilities, people will abandon traditional biomass fuels and turn to adopt high-quality energy in daily life. But much empirical research finds that while 
using high-quality energy, rural residents still consume a lot of low-quality energy such as straw and firewood. China's rural energy policy design mainly focuses on technical policy, such as Eco-household Project, biogas, etc. And the policy system on how to induce a reasonable evolution of rural household energy behavior and improve energy efficiency is not effective enough. Actually, energy consumption decisions of rural household can be divided into two levels. The first is to consider which form or what combinations of energy to be used, and the second is to further consider the consumption level or amount. Therefore, according to the two aspects as well as the quantity consumption behavior of rural residents, in-depth analysis of the effective factors influencing rural energy consumption structure in China will be of great significance in introducing rural energy structure to highquality and clean direction and enhancing the health situation of rural resident.

Therefore, in this paper, we attempt to contribute to the literature by identifying the effective variables that affect energy consumption behavior of rural resident using MLP neural network model and analyzing impact from two aspects of energy choice behavior and quantity consumption behavior based on the field survey data of four typical agricultural provinces in China. This study tries to provide reasonable policy references to improve the structure of rural household's energy consumption so that to reduce carbon emission.

\section{LITERATURE REVIEW}

From the existing literature, most of the research on rural energy mainly focuses on the energy consumption structure, the upgrade of energy consumption and the environmental effect caused by energy consumption [20].

Some studies have concluded that family income, energy resources prices, family demographics, energy availability and geographical features all affect energy consumption decisions. According to Le Chen et al. (2006), the change of mode of rural household energy consumption can alleviate the ecological environment pressure [2]. Meanwhile, increasing the income level of rural households will change their energy consumption varieties and improve their consumption quality accordingly [25].

There is a strong positive correlation between per capita energy consumption and income [22, 27]. However, other studies have also found that the household energy consumption structure of households with different income levels varies a lot [16]. The energy consumption of rural household will eventually shift from non-commercial energy such as straw and fuel-wood to commercial energy. Therefore, differences in income have limited explanatory power to changes in consumer behavior [4]. Some empirical studies of energy expenditure and consumption behavior show that people are more inclined to use cleaner and more efficient energy $[2,26]$. Household income has a significant negative impact on straw consumption and fuel-wood collection.

Energy prices are also the main factors affecting the energy consumption of rural residents [15, 17]. Moreover, the government has an obligation to lower energy prices to meet the basic energy needs of most people [13]. In addition, the initial installation costs of new energy use and the learning costs are also important factors that affect rural household energy consumption, and to a certain extent, these costs inhibited the related energy consumption [6-7].
Family attributes, such as family size, age, educational level and occupational status are also important factors that determine the energy consumption choices of rural household. The average energy consumption of households with larger populations is lower than the average energy consumption of households with less-populated households. A study by [19] on family size and consumption behavior of rural households in Mexico showed that the influence of household size changes on energy consumption behaviour exceeded that of income on consumer behaviour. Similar conclusions also had been made by [20]. In addition, since energy consumption habits will change over time, factors such as age and education level, relating to individual consumption preferences, will have a direct impact on energy choices of farmers [2]. Education level also has a strong relationship with the variety of energy choices $[1,11]$.

The availability of energy resources is another important factor affecting the consumption of farmers. [9] pointed out that during the process of regional economic development, the substitution effect of commercial energy sources on traditional energy sources is strengthening. However, because of the accessibility of traditional non-commercial energy sources, they remain the main options for rural household. [25], [10] considered that the construction of energy infrastructure and energy markets can change the structure of energy consumption by increasing the availability of energy consumption. [5] found that energy infrastructure construction had no meaningful impact on energy consumption and energy mix.

In addition, geographical features, topographical features and temperature are also factors that determine local energy consumption. It is generally believed that the consumption of biomass energy by rural residents in mountainous areas is higher than that in plain areas, while the widespread use of commercialized energy is mainly concentrated in the plain areas. [2] believed temperature had a significant adverse effect on energy consumption, energy consumption declines as temperature increases. However, [28] found there was no significant correlation between commercial energy ratio and annual average temperature by correlation coefficient analysis.

Given the existing literatures, there are three issues that need to be addressed. Firstly, most previous studies employed a single-energy framework to explore the influencing factors. However, due to the differences of varying energy consumption of rural life, the analysis of single energy source may lead to biases in research conclusions and policy implication [14, 29]. Secondly, since the issue of rural energy consumption in China has long been neglected, there is the absence of data available for research. Many current studies are conducted with data on macro or specific region or urban energy consumption $[9,25,29]$. But, urban and rural residents in China have significant differences in lifestyle and energy consumption. Therefore, the conclusions and policy recommendations made for rural households based on the data of energy consumption of urban residents are questionable. Last but not least, the literature shows the extensive study of factors influencing rural household energy consumption [19]. Nevertheless, the rural energy consumption should have two aspects including the choice of energy species and the issue of the amount of consumption. The question of whether there are differences in factors and impact affecting the two aspects behavior is unanswered yet.

To overcome the first limit, we have comprehensively analyzed the various energy types of energy consumption of 
rural households in China, including commercial energy such as liquefied gas, electricity, natural gas and coal, noncommercial energy such as straw, fuel-wood, biogas. Besides, to settle the second issue, the paper collects basic data of four typical agricultural regions through household questionnaire surveys. And a total of 1348 survey questionnaires are collected, of which 1126 are complete samples with all kinds of data and are divided into two parts according to energy types, namely, commercial energy and non-commercial energy. The factors and impact may have different performance of different energy species, which is especially important for policy makers. Additionally, to address the third issue, there are two tasks should be done. On one hand, in this paper, both choice and quantity behavior of energy use are considered, on the other hand, logit model is adopted to analyze fuel choice behavior of rural household while Tobit and multiple regression model are used to analyze energy quantity behavior.

The contributions of this paper are three folds: First, we use a pool energy consumption data from household questionnaire surveys in four typical agricultural regions in China. According to the knowledge of the authors, there are few studies covering Shandong, Hubei, Hunan and Sichuan provinces which are typical and important agricultural regions in China to analyze rural household energy consumption as we do. Second, lots of existing literatures have explored the factors affecting rural household energy consumption, however, most of them considered only the quantity behaviour in researches. In this paper, both choice and quantity behaviour of energy use are considered as an overall framework. Apart from analyzing the factors impact on rural household energy consumption, the differences of impact is also the focus of our analysis, originally. Third, the factors that affect the energy consumption of rural households are very complicated and numerous. According to a large number of sample surveys, the paper constructs a three-layer MLP neural network method to identify the effective variables.

The following part of the paper is organized in three sections: After introduction and literature review, Section 3 shows our survey analysis. Section 4 carries out an empirical analysis and demonstrates main finds. Section 5 is conclusion and policy recommendations.

\section{SURVEY ANALYSIS}

According to regional differences in economic development level, nature, climate and energy availability, four typical agricultural regions including Shandong, Hubei, Hunan and Sichuan provinces were chosen as the research objects.

In our opinions, the typical agricultural region is mainly considered from the contribution of agricultural output value and the population of agricultural labor force rather than regions division. These four provinces are critical agricultural regions in China. In terms of agriculture output, Shandong, Sichuan, Hubei, and Hunan provinces ranks first, 5th, 7th and 8th respectively in China, according to China national statistical yearbook of 2017. Furthermore, the population of agricultural labor force of these four provinces is sequenced first, second, 10th and 6th in turn. The sample is different from previous studies according to economic zones division [25] or the traditional division of eastern China, central China and western China. Surveys according to economic zones division may have covered the whole nation, but may 1 be too scattered to reveal the fundamental relationship between influencing factors and energy consumption behavior of rural household. And investigation according to eastern China, central China and western China, may be too oversimplifying and sketchy. In this paper, being fully acknowledged the unbalanced economic development status and the contributions of agriculture output in China, these four typical regions are chosen as our survey areas.

Such sample also reflects the various degrees and stages of regional economic development. Relatively developed areas are represented by Shandong province, Hubei and Hunan provinces are comparatively developed areas while Sichuan province represents under-development area. Moreover, the four typical agricultural provinces are undergoing the process of rapid urbanization. The structure of rural energy consumption is also in the process of rapid change, which provides abundant materials for investigation and observation. What's more, different geographical features and unique climatic conditions of plains, mountains and hills are taken into consideration during sampling.

From each province, three counties are randomly selected determined by comprehensive analysis on district, environment, resources, economic development level, urbanization and rural household energy consumption. In each county, 120 rural families ( 2 towns, 3 villages of each town and 20 families of each village) were chosen randomly. Thus, a total of 1348 survey questionnaires are collected, of which 1126 are complete samples of all kinds of data, and the proportion of valid samples reaches $83.5 \%$.

Based on the survey, the coexistence of commercial energy (including liquefied gas, electricity, natural gas and coal) and non-commercial energy (straw, fuel-wood and biogas) is an important feature of rural household energy consumption. New energy includes solar energy (Table 1). Due to the low proportion of solar energy, the following analysis is being conducted without solar energy. All the data of energy consumption in the subsequent tables are in the form of annual per capita tons of standard coal.

Table 1. Rural energy classification

\begin{tabular}{ccc}
\hline \multirow{2}{*}{$\begin{array}{c}\text { commercial } \\
\text { energy }\end{array}$} & $\begin{array}{c}\text { high-quality } \\
\text { energy }\end{array}$ & $\begin{array}{c}\text { liquefied gas, electricity, } \\
\text { natural gas }\end{array}$ \\
\cline { 2 - 3 } & $\begin{array}{c}\text { low-quality } \\
\text { energy }\end{array}$ & coal \\
non-commercial & $\begin{array}{c}\text { biomass } \\
\text { energy }\end{array}$ & Straw, firewood, biogas \\
new energy & Solar energy \\
\hline
\end{tabular}

Overall, electricity is universal in rural areas. In our survey, all rural households adopt electricity, followed by coal, accounting for $61.6 \%$ of the total samples and then straw and fuel-wood $41.8 \%$. The proportion of liquefied gas is $38.4 \%$ and the biogas is $7.65 \%$ (Figure 1 ).

In general, the trend of diversification of rural energy consumption is obvious, and mainly derives from commercial energy consumption. To outline the basic factors of changes in rural residents' energy consumption, coal and electricity, LPG and biomass consumption are separately grouped according to the dimensions of household per capita income, per capita arable land, energy accessibility (market distance), family size, highest educational level of family head and geographical features to reveal the inner correlation.

Firstly, the income levels of rural household in the sample areas are arranged from low to high according to classification 
of China Agriculture Statistics Yearbook. The samples are divided into the following five groups, $1500 ¥$ or less, 1500 $2000 ¥, 2000-3000 ¥, 3000-4000 ¥, 4000 ¥$ or more. From Table 2 , the per capita consumption of various energy sources shows a certain trend with the change of income. The per capita consumption of traditional energy sources, such as firewood and straw, decreases significantly with the increase of the income level. From the lowest income group's 0.192 Tons of standard coal down to the highest income group of 0.0401 tons of standard coal, a difference of nearly 5 times. While, the consumption of LPG and electricity shows a clear upward trend as income increases. LPG consumption mainly concentrates in the higher income group of a per capita income of more than 3,000 Yuan, while other groups are less. As can also be seen from the table, the change in coal consumption does not show a monotonous trend, but the highest usage is mainly concentrated in middle-income groups and declines gradually as incomes increase. Coal consumption is the largest among several energy sources, which is consistent with China's main coal-based energy consumption pattern. The use of energy such as firewood and straw by middle-income groups still occupies a considerable proportion; and as income increases, rural residents gradually shift to high-quality commercial energy sources such as LPG and electricity.

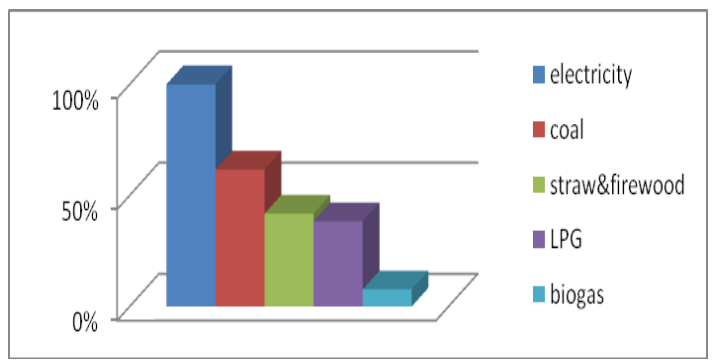

Figure 1. the proportion of different energy options in sample regions

In addition, a multiple energy use pattern exists in rural China, which is consistent with the findings of previous studies [18, 21, 23, 25].

Among them, the pattern of coal and electricity is the most common mode of rural household, accounting for $54.33 \%$, the following is the pattern of straw and coal and electricity, accounting for $42.67 \%$. The mix pattern of LPG, coal, electricity and straw consumption accounts for $31.28 \%$. The pattern of biogas, electricity and coal consumption only accounts for $7.37 \%$ (Figure 2).

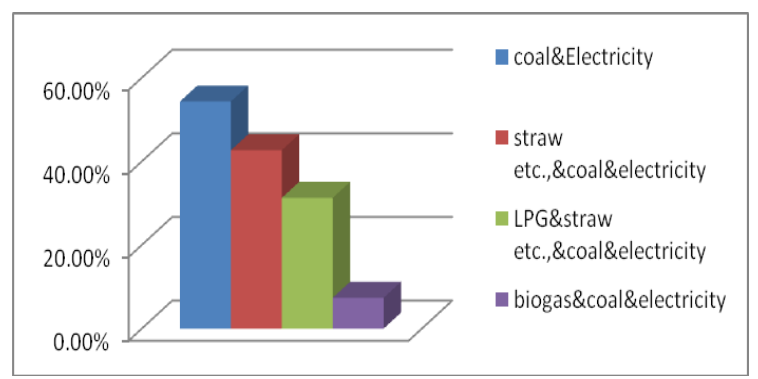

Figure 2. The patterns of energy consumption in sample regions
Table 2. Grouping by per capita household income

\begin{tabular}{ccccc}
\hline & Coal & LPG & Electricity & $\begin{array}{c}\text { bio- } \\
\text { mass }\end{array}$ \\
\hline 1500¥ or less & 0.297 & 0 & 0.16 & 0.1920 \\
$1500-2000 ¥$ & 0.267 & 0.003 & 0.19 & 0.1380 \\
$2000-3000 ¥$ & 0.371 & 0.009 & 0.22 & 0.0709 \\
3000-4000¥ & 0.248 & 0.037 & 0.37 & 0.0398 \\
4000¥ or more & 0.167 & 0.052 & 0.46 & 0.0401 \\
\hline
\end{tabular}

Furthermore, in accordance with per capita family arable land area of 0.5 mu or less, 0.5-0.7 mu, 0.7-0.9 mu, 0.9-1.3 mu and $1.3 \mathrm{mu}$ or more, the samples are also divided into five groups (Table 3). We find that the use of straw increases with the increase of arable land area when the per capita arable land area is less than $1.3 \mathrm{mu}$. However, when the arable land area is more than $1.3 \mathrm{mu}$, the use of straw decreases from 0.127-ton standard coal to 0.068in the group of 0.9-1.3mu. Comparing the highest and least per capita family arable land groups, the difference of coal consumption is nearly 6 times. And there is a clear negative correlation between the use of LPG and the area of arable land. Household whose arable land area is less than $0.5 \mathrm{mu}$ are 7 times of those more than $1.3 \mathrm{mu}$. Thus, rural household with larger arable land are more likely to use traditional energy sources such as straw and coal, while those with less arable land consume less low-quality energy and shift to high-quality energy sources such as LPG.

Also, according to the market distance of $1 \mathrm{~km}$ or less, 1-3 $\mathrm{km}, 3-6 \mathrm{~km}, 6-8 \mathrm{~km}$ and $8 \mathrm{~km}$ or more, the samples are also divided into five groups (Table 4). The amount of coal consumption is positively related to the market distance. Households with average per capita consumption of 0.351 tons of standard coal are the farthest from the market. Generally, rural residents who are far-from-market are much poorer in China. Coal as a high availability energy are easy to buy and can be stored for a long time. So that, coal becomes the preferable choice for families far from market. However, the situation of LPG is different from that of the coal. The consumption of LPG not only requires supporting stoves with relatively high cost, but also needs gas tanks that can be changed easily. This shows that the degree of transportation convenience will change the availability of resources, and ultimately affects the choices of energy.

Table 3. Grouping by per capita arable land area

\begin{tabular}{ccccc}
\hline & Coal & LPG & Electricity & Biomass \\
\hline $0.5 \mathrm{mu}$ or less & 0.068 & 0.042 & 0.033 & 0.053 \\
$0.5-0.7 \mathrm{mu}$ & 0.137 & 0.023 & 0.036 & 0.062 \\
$0.7-0.9 \mathrm{mu}$ & 0.228 & 0.013 & 0.024 & 0.106 \\
$0.9-1.3 \mathrm{mu}$ & 0.317 & 0.006 & 0.017 & 0.127 \\
$1.3 \mathrm{mu}$ or more & 0.408 & 0.006 & 0.015 & 0.068 \\
\hline \multicolumn{5}{l}{ Note: $\mathrm{mu}$ is a traditional unit of area in China, equivalent to 0.165 acre }
\end{tabular}

Table 4. Grouping by market distance

\begin{tabular}{ccccc}
\hline & Coal & LPG & Electricity & Biomass \\
\hline $1 \mathrm{~km}$ or less & 0.161 & 0.03 & 0.039 & 0.08 \\
$1-3 \mathrm{~km}$ & 0.214 & 0.02 & 0.028 & 0.04 \\
$3-6 \mathrm{~km}$ & 0.297 & 0.005 & 0.021 & 0.157 \\
$6-8 \mathrm{~km}$ & 0.261 & 0 & 0.015 & 0.149 \\
$8 \mathrm{~km}$ or more & 0.351 & 0 & 0.012 & 0.127 \\
\hline
\end{tabular}


Table 5. Grouping by family size

\begin{tabular}{ccccc}
\hline & Coal & LPG & Electricity & Biomass \\
\hline 2 & 0.357 & 0.026 & 0.037 & 0.091 \\
3 & 0.224 & 0.027 & 0.041 & 0.057 \\
4 & 0.264 & 0.017 & 0.022 & 0.127 \\
5 & 0.167 & 0.026 & 0.031 & 0.081 \\
6 & 0.243 & 0.007 & 0.018 & 0.091 \\
7 or more & 0.291 & 0.005 & 0.014 & 0.063 \\
\hline
\end{tabular}

In addition, according to the family size of 2, 3, 4, 5, 6, more than 7 persons, the samples are divided into 6 groups (Table 5 ). The consumption of all kinds of energy does not show a clear trend of change with the increase of family size. For families of 4 people, comparing with families of 3 and 5 persons, the consumption of straw, firewood and coal is much higher, especially the straw and firewood. But the amount of LPG and electricity is far less than that of the other two groups.

Moreover, according to education level of household head, such as below elementary school, middle school and college or above, the samples are divided into 3 categories (Table 6). The amount of straw, firewood and coal shows a clear downward trend with the improvement of education levels, while the consumption of LPG and electricity illustrates a marked increase.

The education level of rural residents is positively related to the consumption of clean energy instead of low-quality energy. The possible cause may be the cost of biomass collection and the improvement of environmental awareness and health awareness with increasing education level.

Table 6. Grouping by education level of household head

\begin{tabular}{c|c|c|c|c}
\hline & Coal & LPG & Electricity & Biomass \\
\hline $\begin{array}{c}\text { Elementary school or } \\
\text { less }\end{array}$ & 0.674 & 0.012 & 0.021 & 0.527 \\
\hline Middle school & 0.562 & 0.019 & 0.039 & 0.257 \\
\hline College or more & 0.169 & 0.027 & 0.033 & 0.069 \\
\hline
\end{tabular}

Finally, with the geographic features of mountain, hill and plain, the samples data can be organized into 3 groups (Table 7). The researches reveal that following the altitude increase, the proportion of biomass energy sources increases in turn, while electricity and LPG consumptions display an opposite trend. However, the difference in coal consumption is not obviously significant.

Table 7. Grouping by geographic features

\begin{tabular}{c|c|c|c|c}
\hline & Coal & LPG & Electricity & Biomass \\
\hline Mountain & 0.063 & 0.0019 & 0.004 & 0.061 \\
\hline hill & 0.061 & 0.0042 & 0.006 & 0.033 \\
\hline plain & 0.068 & 0.008 & 0.009 & 0.009 \\
\hline
\end{tabular}

Some preliminary findings derived from the description of sample data can be obtained. First of all, rural household income level plays a vital role in the consumption of energy source. With the increasing of income level, rural residents gradually reduce the consumption of straw and firewood and turn to increase the consumption of clean energy. Secondly, the impact from the respective of arable land area on energy consumption is opposite to the effect of household income. The more arable land area a family has, the more willingness it has to use straw or firewood for living. Otherwise, the family will shift to consume non-commercial energy. For the consumption of LPG, market distance has a negative effect. It is also evident that educational level and geographical features are also important factors affecting rural household energy consumption. However, family size has no significant effect on energy consumption.

\section{EMPIRICAL ANALYSIS AND RESULTS}

\subsection{Variables selection model based on multilayer perceptron neural network}

In order to avoid interference by subjective factors and weaken priori hypothesis, the paper applies neural network to analyze the contribution of all input variables and then removes factors that are not significant or unimportant, so as to establish a reasonable and effective model to analyze the impact of effective variables on rural energy consumption of the aspects of choice and quantity behavior.

Multilayer Perceptron (MLP) is a feed-forward neural network that maps input datasets to a set of appropriate outputs, which has significant performance in variable selection and model accuracy [23]. Fig.3 shows the structure of three-layer MLP that consist an input layer, a hidden layer and an output layer.

If the activation functions of each neuron are linear functions, the MLP of any number of layers can be approximately reduced to an equivalent single layer perceptron.

In fact, MLP itself can use any form of activation functions, such as the ladder function or the logical sigmoid function, but the activation function must be restricted to the differentiable function in order to use the back-propagation algorithm for effective learning. Because of the good differentiability, many sigmoid functions, especially the hyperbolic tangent function and the logical sigmoid function, are used as the activation functions.

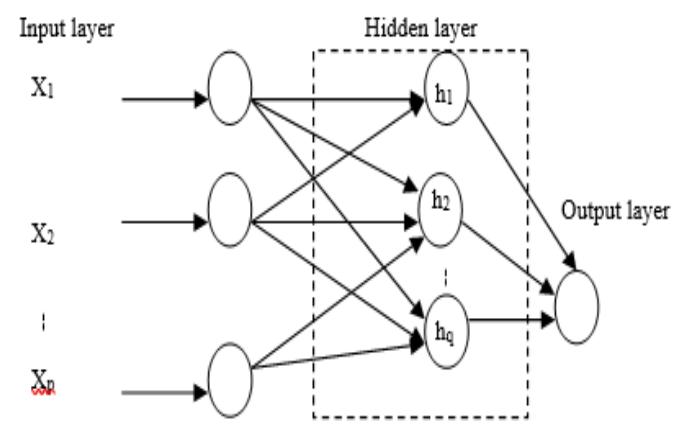

Figure 3. Structure of MLP

Assume that the input variables of the network are given by the candidate variables $\mathrm{x}=\left\{\mathrm{x}_{1}, \mathrm{x}_{2}, \cdots, \mathrm{x}_{\mathrm{p}}\right\}$, and the hidden layer has q nodes, denoted by $h=\left\{h_{1}, h_{2}, \cdots, h_{q}\right\}$. The bias of the jth neuron of the hidden layer is denoted by $\mu_{\mathrm{j}}^{\mathrm{h}}$. The weight $\omega_{\mathrm{ij}}(\mathrm{i} \in[1, \mathrm{p}], \mathrm{j} \in[1, \mathrm{q}])$ represents the input weight between the input variable $x_{i}$ and the $j$ th hidden nodes $h_{j}$. The output results can be obtained by

$O_{j}^{h}=f\left(\left(\sum_{i=1}^{p} \omega_{i j} x_{j}\right)+\mu_{j}^{h}\right)$ 
where $\mathrm{f}$ represents the activation function of hidden layer.

An improved model selection criterion, named AICc, is employed for the task of model selection in this paper. The model selection criterion is formulated as

$$
A I C_{c}=n * \log \left(\frac{1}{n} \sum_{i=1}^{s}\left(\hat{y}_{i}-y_{i}\right)^{2}+2 m+\frac{2 m(m+1)}{n-m-1}\right.
$$

where $\mathrm{s}$ is total number of validation data samples, $\mathrm{m}$ is the number of variables in the model, and $y$ and $\hat{y}$ are the measured and predicted values of the model, respectively.

According to the influencing factors of rural household energy consumption behavior, based on the principle of MLP neural network, an adaptive variables selection model is designed. Through the training of a large number of change samples, the change rules and properties change rules of various influencing factors of rural household energy consumption behavior are learned under different topological relationships and different attributes, and the knowledge and experience are organized to form a database of change knowledge and rules. When the new change survey data is input into the model again, the topology, attributes and linkage influence factors of the input samples can be obtained through the analysis function. These factors are put into the form of vector $\mathrm{X}_{\mathrm{i}}=\left(\mathrm{x}_{1}, \mathrm{x}, \cdots, \mathrm{x}_{\mathrm{n}}\right)$, and then are entered into the model. According to the topology, attribute and linkage characteristics of the new input sample, the adaptive model can make a correct inference to the update strategy and the attribute updating strategy of the new input samples by using the learned experience. Finally, the update strategy corresponding to the sample is given in the form of $Y_{i}=$ $\left(\mathrm{y}_{1}, \mathrm{y}_{2}, \cdots, \mathrm{y}_{\mathrm{n}}\right)$ output vector.

The adaptive variables selection model is divided into at least 3 levels as shown in Figure 4.

The connection weights of the initial values of the neural network is essential for neural network learning, it will directly influence the learning efficiency of the neural network and the speed of training. The connection weight between neurons should not be too large or too small. According to a commonly used heuristic method of weight setting, the connection weight should be a random number from $-0.5 / \mathrm{N}$ to $0.5 / \mathrm{N}$, where $\mathrm{N}$ represents the total number of weights fed by neurons.

According to the actual experience, the variables selection automatically updates every neuron of the neural network, although there is a variety of information, but only a few information will play a role in the neuron. At the same time, the threshold function between the excitation functions used by each neuron is $0 \sim 1$, and the threshold value of each function $\theta=0.5$ is set, where all the initial values of the connection weights are set to 0.25 .

The adaptive variables selection model is composed of multilayer neurons, and the activation conditions of each neuron are known, so the model is essentially a multilayer perceptron neural network. So the training of the model should be carried out layer by layer. Firstly, the input condition is used as the training signal, and the connection weight is trained by the fastest descent method, and then the analogy is carried out until the connection weight of the attribute strategy is completed.

The specific training methods are as follows: A set of training samples $\left(\mathrm{x}^{\mathrm{p}}, \mathrm{T}^{\mathrm{P}}\right)$ for the model are given, where $\mathrm{x}^{\mathrm{p}}$ represents $\mathrm{P}$-th input vector sample, $\mathrm{T}^{\mathrm{P}}$ represents the corresponding output target expectation information, $\mathrm{y}^{\mathrm{p}}$ is the output of the $x^{p}$ on the network, if $y_{j}^{p}=T_{j}^{p}$, the original weight of connection remains unchanged. If $y_{j}^{p} \neq T_{j}^{p}$, the connection weights need to be adjusted according to the Hebb rule. The adjustment $\Delta \mathrm{w}_{\mathrm{ij}}$ is directly proportional to the product of input and output corresponding to the connection weight.

$$
\begin{aligned}
\Delta w_{i j} & =\eta\left(1-y_{j}^{p} T_{j}^{p}\right) T_{j}^{p} x_{j}^{p} \\
& =\eta\left(T_{j}^{p}-y_{j}^{p} T_{j}^{p} T_{j}^{p}\right) x_{j}^{p} \\
& =\eta\left(T_{j}^{p}-y_{j}^{p}\right) x_{j}^{p}=\eta \delta_{j}^{p} x_{j}^{p}
\end{aligned}
$$

where $\delta_{j}^{p}=\left(T_{j}^{p}-y_{j}^{p}\right)$, it represents the output error of the $\mathrm{P}$ th sample network. $\eta$ represents learning rate, the range of its value is from 0 to 1 . $T_{j}^{p}$ is discrete value, $x_{j}^{p}$ can be discrete or continuous values.

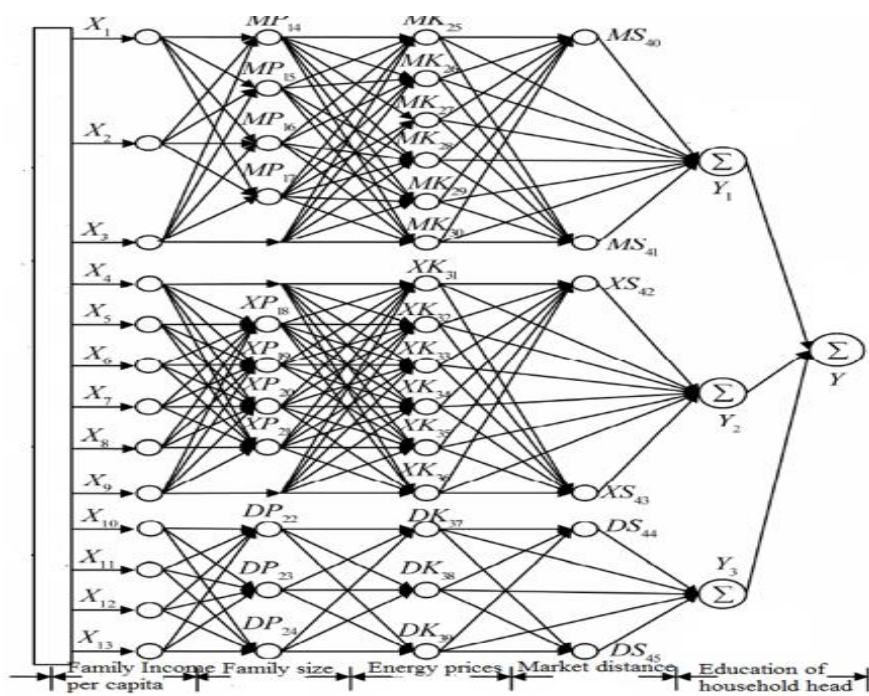

Figure 4. The adaptive variables selection based on multilayer perceptron

\subsection{Regression models}

The factors of adopting energy for rural household which will be used as input of multilayer perceptron neural network are determined by regression analysis. The dependent variable is in dichotomous (dummy) form. Therefore, the binary logic model is the most suitable econometric tool for analysis.

In order to analyze rural household fuel using behavior from the perspective of choice and quantity, authors adopt logit model to analyze fuel choice behavior of rural household, and due to the fact that not every household consume fuel of straw, firewood or LPG, Tobit model is used to reveal the fundamental mechanism of choice and quantity energy consumption behavior change. However, in the analysis of electricity, general regression model is an appropriate tool since every rural household in the sample adopted electricity as the demand of cooking, lighting or heating. The general regression model is specified as:

$$
Y=\alpha+\beta_{1} X_{1}+\beta_{2} X_{2}+\ldots \ldots \ldots+\beta_{k} X_{k}+\varepsilon \varepsilon \sim N\left(0, \delta^{2}\right)
$$

where $\mathrm{Y}$ is dependent variable, $\mathrm{X}_{\mathrm{n}}(\mathrm{n} \in[1 \cdots \mathrm{k}])$ is a vector of independent variables. The logit model based on the logistic distribution is specified as: 


$$
\begin{aligned}
& P_{i}=E\left(\mathrm{Y}=1 \mid X_{i}\right)=\mathrm{F}\left(\mathrm{Z}_{\mathrm{i}}\right) \\
& =\mathrm{F}\left(\alpha+\sum_{i=1}^{n} \beta_{i} X_{i}\right)=\frac{1}{1+e^{-Z}}
\end{aligned}
$$

where

$\mathrm{Z}_{\mathrm{i}}=\ln \frac{P_{i}}{1-P_{i}}=\alpha+\sum_{i=1}^{n} \beta_{i} X_{i}+\varepsilon_{i}$

$\beta_{\mathrm{i}}=$ the coefficients of the explanatory variables to be estimated, and usually estimated by the maximum likelihood procedure, In $\frac{P_{i}}{1-P_{i}}=$ which is the $\log$ odds ratio of the probability that a household adopts certain energy source, $\mathrm{X}_{\mathrm{i}}=$ the explanatory variables, $\mathrm{e}=$ the base of the natural logarithm, $\varepsilon_{\mathrm{i}}=$ the stochastic error term.

However, in order to describe the relationship between a non-negative dependent variable and an independent variable, tobit model was proposed by James Tobin in 1958. The model assumes a latent variable $Y_{i}$. This variable is linearly dependent on $X_{i}$ by the parameter (vector) $\beta_{i}$, which determines the relationship between the independent variable and the underlying variable (just as in the linear model). In addition, there is a normally distributed error term to capture the random effects on this relationship. The observed variable is defined to be equal to the latent variable whenever the latent variable is above zero and zero otherwise.

$Y_{i}=\left\{\begin{array}{cc}Y_{i}^{*} & Y_{i}^{*}>0 \\ 0 & Y_{i}^{*} \leq 0\end{array}\right.$

where $\mathrm{Y}_{\mathrm{i}}^{*}$ is a latent variable, and can be written as:

$Y_{i}^{*}=\alpha+\beta_{1} X_{1}+\beta_{2} X_{2}+\ldots \ldots \ldots+\beta_{k} X_{k}+\varepsilon_{i}, \varepsilon_{i} \sim N\left(0, \delta^{2}\right)$

\subsection{Variables}

There were 1126 effective samples investigated in four typical agricultural provinces in this paper, in which 750 samples were training data, and the other 376 samples were testing data. Through the above algorithm, using AICC as the determination, after iterating over 10,000 times, and controlling the systematic error 0.006 , the paper analyzes the contribution rate of the candidate variables, eliminates the variables that have weak or no influence, and the effective variables are finally shown in the table 8 .

This article applies the geometric average of the prices of coal, LPG and electricity as variables of Aprice of commercial energy price. But in the LPG measurement model, considering the mutual-substitution of LPG, coal and electricity, coal price (Cprice), LPG price (Lprice) and electricity price (Eprice) are usedas independent variables. To reduce heteroskedasticity, all variables are in logarithmic form, except dummy variables.

\subsection{Fuels varieties choice behavior analysis}

The empirical results of fuels varieties choice behavior are reported in Table 9 based on logit model. In our analysis, straw and firewood represent traditional biomass fuel sources, and LPG represents clean energy. The columns 1-2 present the results of biomass with straw, firewood and LPG respectively.
In the model of biomass, variable of energy price (Aprice) is in the form of geometric average of the energy prices of coal, LPG and electricity. While in order to capture the substitution of LPG and coal consumption, variables of Lprice (LPG price) and Cprice (coal price) are considered in the LPG estimated model.

According to Table 9, household per capita income has a significant negative effect on the choice of non-commercial energy at 5\% level when controlling other factors. The estimated coefficients are -0.2408 for straw and firewood and 0.7102 for LPG. Thus, an increase in the level of rural household income leads to cleaner commercial energy consumption. Boosting the income level of rural residents is an effective way to improve energy structure. This finding is consistent with the results reported in previous studies, including those of [20] and [26].

The effect of commercial energy price on biomass fuel choice is positive and significant at level $10 \%$ with the coefficient of 0.1507 . One reason for increasing the energy price is the relatively decrease of household income. Poorer households are more sensitive of energy price. The other is that the poorer families are more willing to spend their time collecting straw or firewood, instead of purchasing commercial energy sources because of limited energy budget. While coal price is positive on LPG choice, means increasing coal price leads to the increase possibility of LPG consumption for rural residents. That is most families using LPG in the sample are wealthier. People are not willing to consume coal that causes indoor pollution or health problem and are more likely to adopt clean energy.

\begin{tabular}{|c|c|c|}
\hline Variables & Description & Note \\
\hline 1 & $\begin{array}{l}\text { Family Income } \\
\text { per capita }\end{array}$ & \\
\hline 2 & $\begin{array}{l}\text { arable land } \\
\text { acreage per } \\
\text { capita }\end{array}$ & $\begin{array}{l}\text { accessibility of non-commercial } \\
\text { energy }\end{array}$ \\
\hline 3 & $\begin{array}{l}\text { Geographic } \\
\text { features }\end{array}$ & $\begin{array}{l}\text { GEOCHA as mountain regions, } \\
\text { GEOCHC as hill regions, } \\
\text { GEOCHC as plain regions }\end{array}$ \\
\hline 4 & Family size & \\
\hline 5 & Energy prices & $\begin{array}{c}\text { Coal price, LPG price, electricity } \\
\text { price }\end{array}$ \\
\hline 6 & $\begin{array}{l}\text { Education of } \\
\text { household head }\end{array}$ & $\begin{array}{c}\text { EDUA as college level or above, } \\
\text { EDUB as middle school, EDUC } \\
\text { as elementary school }\end{array}$ \\
\hline 7 & $\begin{array}{l}\text { Occupation of } \\
\text { household head }\end{array}$ & $\begin{array}{c}\text { CarrA means farmers, CarrB as } \\
\text { temporary job of non-agricultural } \\
\text { employment, CarrC as two kinds } \\
\text { both. }\end{array}$ \\
\hline 8 & $\begin{array}{r}\text { Market } \\
\text { distance }\end{array}$ & $\begin{array}{l}\text { accessibility of commercial } \\
\text { energy }\end{array}$ \\
\hline
\end{tabular}

Table 8. Results of variables selection by MLP

The effects of arable land area per capita on the choice of biomass and LPG are contrast. The impact with 0.3439 on biomass is positive, while with -0.5174 on LPG choice. The increase of arable land positively influences the energy choice behavior of biomass and it is negative to the choice of LPG. Similar results are reported in Table 9 with the variable of family size. Large families are more willing to adopt straw and firewood to meet their needs, instead of LPG source. As we know, family size is an important basis for rural land distribution in China. The larger the family size is, the more the total land area of household will be arranged. Under the 
condition of more arable land area, they would rather use straw or firewood than other commercial energy for cooking, heating or other purpose.

Geographical features have a significant impact on both non-commercial and commercial energy choices. Rural residents living in the mountain regions are more likely to consume biomass fuels and less likely to adopt LPG as living energy demand. In China, rural household in the mountain regions are far from the energy market and have a higher cost to access commercial energy. Especially, most of them lives below poverty lines, thus, they would rather spend more time collecting biomass fuels as their main living energy. The occupation and education level of household head also affects energy choice. Firstly, education level of household head influences biomass fuel choice negatively, while the effect is positive on LPG choice. Obviously, improving education helps increase the possibility of clean energy adoption and assists to improve energy structure. Secondly, occupation of household head has a positive effect on biomass fuels choice, especially those families only based on farming. However, the impacts of occupation on LPG choice are not significant. For most rural residents in China, their incomes are not only from farming but also from non-agricultural jobs, different jobs mean different incomes. Because of low return of agricultural labor, most rural young inhabitants migrate to cities in anticipation of better living, leaving their old parents and kids in rural areas. This is a very common phenomenon in China. Their energy consumption patterns are more influenced by urban citizens to adopt clean energy.

Table 9. Estimation of energy choice behavior with Logit model

\begin{tabular}{c|c|c}
\hline & Biomass & LPG \\
\hline Constant & 0.1662 & -2.3981 \\
\hline Ln (Income) & $-0.2408^{*}$ & $0.7102^{*}$ \\
\hline Ln (RPland) & $0.3439^{* *}$ & $-0.5174^{* *}$ \\
\hline Ln (population) & $0.6134^{*}$ & -0.6547 \\
\hline Ln (Aprice) & $0.1507^{* *}$ & - \\
\hline Ln (Lprice) & - & 0.1516 \\
\hline Ln (Cprice) & - & 0.7639 \\
\hline Ln (Distant) & - & -0.8236 \\
\hline Education: EDUA & $-1.096^{*}$ & $2.1968^{*}$ \\
\hline Education: EDUB & $0.3432^{*}$ & $1.3592^{* *}$ \\
\hline Education: EDUC & $0.9023^{* *}$ & $0.0185^{* *}$ \\
\hline GEOCH: GEOCHA & $1.0852^{*}$ & $-8.8435^{* *}$ \\
\hline GEOCH: GEOCHB & $-0.9258^{*}$ & $-5.1496^{* *}$ \\
\hline GEOCH: GEOCHC & $-0.4133^{*}$ & $-3.2695^{* *}$ \\
\hline Carr: CarrA & $0.3311^{* *}$ & -0.5139 \\
\hline Carr: CarrB & $0.1491^{* *}$ & 0.3287 \\
\hline Carr: CarrC & $0.1906^{* *}$ & 0.1971 \\
\hline
\end{tabular}

Note: * ** indicates rejection of null hypothesis at level of $5 \%$ and $10 \%$

\subsection{Fuels quantity behavior analysis}

The empirical results of fuels quantity behavior are reported in Table10. Biomass, coal and LPG quantity analysis adopt Tobit model, general linear regression model is for electricity consumption analysis.

Household income per capita has a positive link with the consumption amount of LPG and electricity, with coefficients of 1.2592 and 0.1725 respectively, while is a negative relationship with biomass, with a coefficient of -1.8572 . The increase of income obviously inhibits the consumption of traditional energy and leads farmers to switch to cleaner energy consumption such as LPG or electricity. But it is not significant with coal consumption. As a fuel source, the amount of coal consumption in rural areas has not apparent trend with income is easily understood. Coal consumption amount is the largest share of China energy structure and the most accessible fuel. For most rural residents, they have no choice but to adopt coal, regardless of whether income increases.

Table 10. Estimation of energy consumption quantity behaviour with Tobit and GLM models

\begin{tabular}{|c|c|c|c|c|}
\hline & Biomass & Coal & LPG & Electricity \\
\hline Constant & -2.4781 & -14.1436 & -19.8283 & 0.1662 \\
\hline Ln(Income) & $-1.8572^{*}$ & -0.4274 & $1.2592 * *$ & $0.1725^{*}$ \\
\hline Ln(RPland) & $1.6654 * *$ & -0.2501 & -1.6293 & 0.0811 \\
\hline Ln(Population) & $1.9130 *$ & 0.06591 & -0.6052 & $-0.005 * *$ \\
\hline Ln(Price) & $1.0811^{* *}$ & & -1.4806 & \\
\hline Ln(LPrice) & & $3.2891 *$ & -1.0837 & $0.8401 * *$ \\
\hline Ln(Cprice) & & -3.1462 & & \\
\hline Ln(EPrice) & & & & -1.4084 \\
\hline Ln(Distance) & & $-0.0716^{*}$ & -0.5045 & $-0.0902 *$ \\
\hline $\begin{array}{l}\text { Education: } \\
\text { EDUA }\end{array}$ & $-8.7632 *$ & $1.0819 *$ & 11.0421 & 0.1961 \\
\hline $\begin{array}{l}\text { Education: } \\
\text { EDUB }\end{array}$ & $-6.2567 *$ & $0.8892 *$ & 10.9142 & 0.1635 \\
\hline $\begin{array}{l}\text { Education: } \\
\text { EDUC }\end{array}$ & $-5.9391 *$ & 0.3413 & 10.5236 & 0.1432 \\
\hline $\begin{array}{l}\text { GEOCH: } \\
\text { GEOCHA }\end{array}$ & $7.0092 *$ & $\begin{array}{c}- \\
11.7253 * * \\
\end{array}$ & - & -2.2631 \\
\hline $\begin{array}{l}\text { GEOCH: } \\
\text { GEOCHB }\end{array}$ & $-0.8288^{*}$ & $-9.5165^{* *}$ & $\begin{array}{c}- \\
8.2397 * *\end{array}$ & -0.9487 \\
\hline $\begin{array}{l}\text { GEOCH: } \\
\text { GEOCHC }\end{array}$ & $-4.0167 *$ & $10.0708^{* *}$ & $\begin{array}{c}- \\
6.3247 * * \\
\end{array}$ & $-0.8433 * *$ \\
\hline Carr: CarrA & $1.8807 * *$ & 0.8214 & 1.1188 & 0.3379 \\
\hline Carr: CarrB & $2.3987 * *$ & 0.6413 & 1.9645 & 0.2127 \\
\hline Carr: CarrC & $1.1829 * *$ & 0.4397 & 1.5876 & 0.2836 \\
\hline
\end{tabular}

Family size has impact on the consumption of biomass and electricity. With the increasing of family size, people are willing to adopt biomass fuel and slightly reduce electricity consumption due to restrictions of energy expenditure and energy saving.

As for the aspect of energy price, it is a little more complicated. To reveal the relationship between commercial energy price and biomass consumption, energy price (Aprice) is in the form of geometric average of the energy prices of coal, LPG and electricity, and find that the increasing of commercial energy price makes rural residents turn to adopt low-quality fuels such straw and firewood instead of high-quality commercial fuels. Also, coal has obvious substitution effect on LPG. LPG price increases the amount of coal consumption with an estimated coefficient of 3.2891. In contrast, as mentioned above, coal is a rich and readily available fuel in China, coal price is not significant on the amount of coal consumption. In addition, LPG and coal price have negative link with LPG consumption, although they are not significant at level $5 \%$ or $10 \%$. As for electricity, the rising in LPG price leads to an increase in demand for electricity, which is in line with expectations and reality.

Market distance negatively affects coal, LPG and electricity consumption. However, education level has a positive impact on clean fuels such as LPG and electricity consumption, and a negative link with the consumption amount of straw and 
firewood. This conclusion is consistent with the previous analysis in section 3 and also in other studies of [27].

The variable of cultivated land area only has a positive effect on biomass and does not significantly influence coal, LPG and electricity consumption.

According to the results of Table 10, the dependence of biomass fuels in mountain regions is far higher than other two regions. And also residents in mountain regions are willing to adopt coal and electricity. One reason is coal is easy to be stored and more accessible doe to its relatively low price. The other one is that most areas in China including mountain regions are powered on by Every Village Project. This not only solves the problem of electricity shortage in rural areas, but also reflects the fairness of energy. Moreover, people with non-agriculture jobs are more willing to consume clean fuels instead of dirty energy. The occupation of household head is also an important factor affecting energy consumption.

From the empirical results, some interesting findings can be obtained. Rising income has facilitated households to consume less biomass or traditional energy such as coal and turn to consume more clean energy both on the aspects of choice and quantity behavior. However, the scale of household has an opposite impact on energy consumption behavior. Moreover, improving education helps increase the possibility of clean energy adoption and improve energy structure. The variable of energy price is an important factor affecting energy choice and quantity behavior. Household will adopt more biomass fuels and reduce the consumption of LPG or electricity in term of rising energy price. In addition, the effects of arable land area per capita on the choice of biomass and LPG are contrast both on the aspects of choice and quantity behavior. The results also find that the impacts of per capita income and energy price on coal consumption are not significant.

\section{CONCLUSIONS \& POLICY RECOMMENDATIONS}

Rural household energy consumption in China is undergoing transition from non-commercial to commercial energy source, and energy consumption modes have also become diversified. Income level is a key determinant in the transition to new energy sources and the total energy demand. However, the research finds that the impact of per capita income on coal consumption is not significant. Since coal is the most abundant resource with the largest share in energy consumption structure in china, coal consumption is not sensitive to the elasticity of income changing of rural residents. When the transition is occurring, coal appears to be the principal substitute for biomass fuel for rural residents. It is the insensitivity of coal consumption to the income changing that makes the main increase of energy demand of rural household lies in coal consumption. It is known that coal brings much more carbon emissions than other fuels do. Therefore, confronting the pressure of deteriorating climate environment, tight energy supply and international carbon emissions reduction, rural energy must be included in the national energy strategy framework to consider rural energy development and step up co-ordination of rural energy supply-side reform. It is imperative to vigorously develop clean coal and accelerate the substitution of non-fossil fuels for traditional fossil fuels. This is very urgent for China's rural energy consumption in the process of transformation and upgrading.

Meanwhile, the dominant factors affecting varieties and quantity of rural energy consumption have different mechanisms. It is difficult for the government to control its energy consumption behavior through a system of unified regulatory policy tools, due to the dispersion of energy use by rural residents and the relative independence of household energy use. However, difference of energy endowments, climatic conditions, economic development and living habits all affect the energy consumption behavior of rural residents. Regardless of Eco-household project, biogas, or other new energy policy, they are undoubtedly important measures to improve energy structure and energy-saving emission reduction, but if policy makers ignore the differences among income, energy endowments and geographical features, the emission reduction should not be effective enough. On the other side, as the rational individual of energy consumption, the choice of energy consumption patterns of rural household is to maximize utility. Any kind of energy consumption pattern is a preferred result under the existing conditions. Only relying on the existing rural energy policy to guide rural household to abandon traditional fuel of coal, straw and firewood and to use high-quality energy consumption is unrealistic and contrary to the economic rationality of rural residents. When promoting energy technologies and new energy sources, the government needs more comprehensive utilization of economic measures such as taxes and subsidies to reduce initial installed costs and operating costs to enhance the economy, convenience and comfort of fuel using and to speed up the process of upgrading rural energy consumption structure. Therefore, the rural energy development strategy must also follow the principle of local energy endowments and give full play to the local development of rural energy initiative, to ensure energy fairness, to avoid uniform rural energy policy.

Renewable energy has natural connections with rural energy. Vigorously developing renewable energy will not only enrich rural residents 'sources of energy consumption, but also reduce their reliance on traditional energy sources such as coal and straw firewood, reduce their carbon emissions, and improve energy efficiency as well as the residents' health. Wind energy, solar energy, geothermal resources are more abundant in China. Therefore, developing new energy according to local endowments should be provided with comprehensive support policies such as guaranteed acquisitions, subsidies and taxes to accelerate the transition of rural energy consumption and alleviate the competitive contradiction for commercial energy between urban and rural area, and provide space and time protection for the transformation of the national energy structure. The rural areas in China have abundant biomass energy resources with low utilization. With modern technologies, traditional biomass can be transformed into high-quality energy in the form of liquids, solids or gases. This will not only increase the employment opportunities for rural residents and their incomes, but also realize the internalization of environmental benefits of mitigating and adapting to climate change capabilities and promote the realization of the value of rural energy and environment benefits. In addition, the environmental and health awareness of rural residents is very limited, so education and policy guidance are very necessary.

\section{ACKNOWLEDGEMENTS}

We thank the financial support provided by the National Natural Science Funding of China (71373246, 71273246), Key Projects of Philosophy and Social Sciences Research, 
Ministry of Education of China (15ZD014), Natural Science foundation of Hubei (2015CFB497).

\section{REFERENCES}

[1] Bhojvaid V, Jeuland M, Kar A, Lewis JJ, Pattanayak SK, Ramanathan N, Ramanathan V, Rehman IH. (2014). How do people in rural India perceive improved stoves and clean fuel? Evidence from Uttar Pradesh and Uttarakhand, International Journal of Environmental Research and Public Health 11(2): 1341-1358. https://doi.org/10.3390/ijerph110201341

[2] Chen L, Heerink N, Berg MVD. (2006). Energy consumption in rural China: A household model for three villages in Jiangxi Province. Ecological Economics, 58(2): $407-420$

https://doi.org/10.1016/j.ecolecon.2005.07.018

[3] Cheng S. (2009). Rural energy consumption prediction based on chaos - neural model. Journal of Agrotechnical Economics (3): 67-71.

[4] Cooke P, Köhlin G, Hyde WF. (2008). Fuel-wood, forests and community management-evidence from household studies. Environment \& Development Economics 13(1): 103-135. https://doi.org/10.1017/s1355770x0700397x

[5] Davis M. (1998). Rural household energy consumption: The effects of access to electricity-evidence from South Africa. Energy Policy 26(3): 207-217. https://doi.org/10.1016/S0301-4215(97)00100-6

[6] Fischer SL. (2001). Biomass-derived liquid cooking fuels for household use in rural China: potential for reducing health costs and mitigating greenhouse gas emissions. Energy for Sustainable Development 5(1): 23-30. https://doi.org/10.1016/S0973-0826(09)60017-X

[7] Gwavuya SG, Abele S, Barfuss I, Zeller M, Müller J. (2012). Household energy economics in rural Ethiopia: A cost-benefit analysis of biogas energy. Renewable Energy 48(6): 202-209. https://doi.org/10.1016/j.renene.2012.04.042

[8] Hu S, Yan D, Guo SY, Cui Y, Dong B. (2017). A survey on energy consumption and energy usage behavior of households and residential building in urban China. Energy and Buildings (148): 366-378. https://doi.org/10.1016/j.enbuild.2017.03.064

[9] Jiang LW, O'Neill CB. (2004). The energy transition in rural China. International Journal of Global Energy Issues 21(1-2): 2-26.

[10] Leach G. (1992). The energy transition. Energy Policy 20(2): 116-23. https://doi.org/10.1007/978-3-31950292-2

[11] Li JJ, Zhang Y, Zhang MH, Zheng HM, Xia LL, Sun XX. (2016). Analysis of the energy consumption structure in Shanxi province based on carbon emissions. Journal of Environmental Accounting and Management 4(1): 23-26.

[12] Li X, Liu J, Liu X. (2017). Direct rebound effect for urban household in China-an empirical study. Energy Efficiency 10(6): 1-16. https://doi.org/10.1007/s12053017-9533-4

[13] Lin BQ, Liu C. (2016). Chinese energy subsidy and effective energy subsidies. Social Sciences in China (10): 52-71, 202-03.

[14] Liu H, Jiang GM, Zhuang HY, Wang KJ. (2008). Distribution, utilization structure and potential of biomass resources in rural China: With special references of crop residues. Renewable and Sustainable Energy Reviews 12(5): $1402-1418$ https://doi.org/10.1016/j.rser.2007.01.011

[15] Liu Z, Zhao T. (2015). Contribution of price/expenditure factors of residential energy consumption in China from 1993 to 2011: A decomposition analysis. Energy Conversion \& Management (98): 401-410. https://doi.org/10.1016/j.enconman.2015.04.008

[16] $\mathrm{Lu} \mathrm{H}, \mathrm{Lu} \mathrm{L.} \mathrm{(2006).} \mathrm{An} \mathrm{empirical} \mathrm{analysis} \mathrm{of} \mathrm{the} \mathrm{impact}$ of farmers' income level on the household energy consumption structure in the countryside. Finance and Trade Research (3): 28-34.

[17] Mahadevan R, Asafu-Adjaye J. (2007). Energy consumption, economic growth and prices: A reassessment using panel VECM for developed and developing countries. Energy Policy 35(4): 2481-2490. https://doi.org/10.1016/j.enpol.2006.08.019

[18] Masera OR, Saatkamp BD, Kammen DM. (2000). From Linear fuel switching to multiple cooking strategies: A critique and alternative to the energy ladder model. World Dev 28(12): 2083-103. https://doi.org/10.1016/S0305-750X(00)00076-0

[19] Sheinbaum C, Martinez M, Rodriguez L. (1996). Trends and prospects in Mexican residential energy use. Energy 21(6): 493-504. https://doi.org/10.1016/03605442(96)00011-4

[20] Shi QH, Peng XH, Zhang R. (2014). Fieldwork on rural energy consumption in China: A case study of 2253 farmers in Shanxi. Guizhou and Zhejiang Provinces, Management World (5): 80-91.

[21] Song CH, Bilsborrow R, Jagger P, Zhang Q, Chen XD, Huang QF. (2018). Rural household energy use and its determinants in china: How important are influences of payment for ecosystem services vs. other factors. Ecological Economics (145): 148-159.

[22] Srivastava L, Goswami A, Diljun GM, Chaudhury S. (2012). Energy access: Revelations from energy consumption patterns in rural India. Energy Policy 47(1): 11-20. https://doi.org/10.1016/j.enpol.2012.03.030

[23] Sun K, Huang SH, Wong DS, Jang SS. (2017). Design and application of a variable selection method for multilayer perceptron neural network with LASSO. IEEE Transactions on Neural Networks and Learning Systems (28): 1386-96. https://doi.org/10.1109/tnnls.2016.2542866

[24] Tonooka Y, Liu JP, Kondou Y, Ning YD, Fukasawa O. (2006). A survey on energy consumption in rural households in the fringes of Xian city. Energy \& Buildings $38(11)$ : 1335-1342. https://doi.org/10.1016/j.enbuild.2006.04.011

[25] Wang R, Jiang Z. (2017). Energy consumption in China's rural areas: A study based on the village energy survey. Journal of Cleaner Production (143): 452-461. https://doi.org/10.1016/j.jclepro.2016.12.090

[26] Wang XH, Hao XR, Jin L. (2014). Study on rural household energy consumption in China based on household investigation from typical counties. Transactions of the Chinese Society of Agricultural Engineering 30(14): 206-212. https://doi.org/10.3969/j.issn.1002-6819.2014.14.026

[27] Wang XH, Feng ZM, Bao XF. (1999). Research on energy consumption of well-off rural households in China: Case of Yangzhong city in Jiangsu province. 
Energy Research and Utilization 2(2): 7-12. https://doi.org/10.1016/S0360-5442(97)00042-X

[28] Wang XH, Feng ZM. (2001). Research on rural household energy consumption in China: Consumption level and influencing factors. Transactions of the Chinese Society of Agricultural Engineering 5(3): 88-91.
[29] Zhou Z, Wu W, Chen Q, Chen S. (2008). Study on sustainable development of rural household energy in northern China. Renewable and Sustainable Energy Review 12(8):

https://doi.org/10.1016/j.rser.2007.03.007 